\title{
Competing in Taxes and Investment under Fiscal Equalization
}

J. Hindriks, S. Peralta and Sh. Weber

Discussion Paper 2006-62

\section{Département des Sciences Économiques de l'Université catholique de Louvain}




\title{
Competing in Taxes and Investment under Fiscal Equalization*
}

\author{
Jean Hindriks ${ }^{\dagger} \quad$ Susana Peralta ${ }^{\ddagger} \quad$ Shlomo Weber $^{\S}$
}

November 29, 2006

CORE Discussion Paper 2006/109

\begin{abstract}
The paper considers a model of a federation with two heterogeneous regions that try to attract the capital by competing in capital income taxes and public investment that enhance the productivity of capital. The regions' choices determine the allocation of capital across the regions and their revenues under a tax sharing scheme. This framework allows for the examination of different approaches to fiscal equalization schemes (Boadway and Flatters, 1982, and Weingast, 2006). We show that tax competition distorts (downwards) public investments and that the equalization grants discourage public investments with a little effect on equilibrium taxes. However, the equalization schemes remain beneficial for the federation and, provided that the degree of asymmetry is small, for each region as well.
\end{abstract}

Keywords: Heterogeneous Regions, Fiscal Federalism, Fiscal equalization, Public Investments.

JEL Classification: C72, H23, H70.

*This research was partially supported by the ARC project on Heterogeneity in economics. We acknowledge helpful comments by Kristian Behrens, Georges Casamatta, Giordano Mion, Pierre Picard, Jacques Thisse and participants of the CORE-IDEI conference on Public Economics (Toulouse, May 2005), the Summer School in the Analysis of Heterogeneity in Social Organizations (CORE, June 2005) and the Workshop on Fiscal Federalism (Barcelona, June 2005). Our special gratitude goes to the editor of the journal, Robin Boadway, and two anonymous referees for their insightful comments and suggestions that allowed us to produce a substantially improved version of the paper.

${ }^{\dagger}$ CORE, Université catholique de Louvain.

${ }^{\ddagger}$ Faculdade de Economia, Universidade Nova de Lisboa and CORE, Université catholique de Louvain.

$\S$ CORE, Université catholique de Louvain, SMU and CEPR. 


\section{Introduction}

A large number of federal countries have adopted various equalization schemes that allow central government to address the issue of fiscal imbalances across jurisdictions. The equalization payments are enshrined in the Canadian constitution and are used in Australia, Denmark and Switzerland, and in many developing countries (see Ahmad and Thomas, 1997, Shah, 2004). Another example is Germany, where in addition to the transfers from the federal to state governments, there exists a scheme of transfers across states. In the US, the state tax sharing is one of two forms of state intergovernmental aid to local governments (the other consists of categorical grants-in-aid), which is itself the largest element of state expenditures. In fact, in 2000 the average share of state intergovernmental expenditures in states' general revenues was about one third across the US.

The alleged purpose of these scheme is an attempt to correct fiscal imbalances and equalize the citizens access to public services across jurisdictions. Another reason, outlined by Boadway and Flatters (1982), is that fiscal equalization schemes can generate efficiency gains by internalizing the fiscal externality. The Boadway and Flatters result has been later reinforced in strategic tax setting, ${ }^{1}$ where jurisdictions can alter tax rates in response to equalization policies. Then the federal planner can design intergovernmental transfers to implement the efficient tax rates at the local level. Even though there is no guarantee that all jurisdictions benefit from such transfers and would implement it on a voluntary basis, Hindriks and Myles (2003) have shown that jurisdictions can voluntarily agree to share revenue as a strategic device to limit harmful tax competition.

More recently, the optimistic view of fiscal equalization has been challenged by the socalled second generation of fiscal federalism (Weingast, 2006), which suggests that equalization grants may have perverse fiscal incentives. Namely, local governments are more inclined to provide market-enhancing public goods and to raise tax revenue if they capture a large portion of the generated tax revenue. ${ }^{2}$ Along these lines Shleifer and Vishny (1998) conclude that "the effect of such fiscal federalism are perverse" (p.249) and used this argument in their comparison of economic reforms in China and Russia.

It is important to point out that the two conflicting views are "asymmetric" in their reliance on taxes and public investments. The issue of public investment incentives is not accounted for by the efficiency argument for equalization grants, whereas the "perverse fiscal incentive argument" ignores the capital mobility. In our attempt to merge both theories, we offer a model with both tax and public investment competition. More specifically, there is an economy with a total stock of capital, to be assigned, subject to a participation constraint, to two different localities (regions). In order to enhance the productivity of capital, the regions

\footnotetext{
${ }^{1}$ Bird and Slack (1990), Wildasin (1991), Smart (1998), Kothenburger (2002), Bucovetsky and Smart (2006), Figuières et al. (2004)).

${ }^{2}$ See an empirical literature on the relationship between intergovernmental transfers and local tax effort: Buettner (2006), Dahlby and Warren (2003), Baretti et al. (2002), Hepp and von Hagen (2001), and a theoretical contribution by Bordignon et al. (2001) who show how intergovernmental transfers affect tax enforcement. Several papers have estimated marginal revenue retention rates between 10 and 30 percent for Mexico, Russia and India: see Careaga and Weingast, 2000, Parikh and Weingast, 2003, Zhuravskaya, 2000. A somewhat different estimation result is provided by Jin et al. (2005), who argued that on average Chinese provinces retain 90 per cent of locally generated tax revenue.
} 
commit to local public investments, which attract capital to the region at the expense of its competitor. Note that our setting generates a trade-off between fiscal revenue and the rent from capital, on one hand, and the investment costs, on the other, where both raise with a higher level of public investments. We use the framework of a two-stage game in which regions choose their public investments before setting taxes. This simple setting shows that flows of capital between localities create a non-market inefficient linkage whereby one region's tax base responds to the other region's policy choices.

An important feature of our model is the tax-public investment interaction: regions that offer a more appealing environment for capital, may be more attractive even if they set a higher tax on capital. We find that in equilibrium there is under-investment and undertaxation. While the latter is a standard consequence of fiscal competition for mobile tax base, the under-investment result is less obvious. When the second-stage tax choices are strategic complements, the first-stage commitment in public investments allows the regions to shift the reaction curve in a visible and irrevocable way prior to second stage tax competition. The effect of public investment is to make a region a tougher tax competitor in the second stage of the game. The tax reaction curves are then shifted inwards and each region will set a lower tax in response to every tax choice of the other region. If the initial commitment intensifies the second-stage tax competition, each region is encouraged to under-invest in order to relax the intensity of the second stage rivalry in taxes. This so-called "puppy dog ploy" (Fudenberg and Tirole, 1984) of a commitment in the first stage to behave like "a small, friendly, non-aggressive puppy dog" in the second. Such a strategy softens the tax competition between regions and raises their welfare above the level attainable under a more aggressive stance in the first stage. It is interesting to contrast this observation with the over-provision of public investment versus public goods in the simultaneous game examined by Keen and Marchand (1997). The reason for such distortion in the composition of public spending is that public good impacts only residents of the region whereas public investments attract capital away from other regions. Such negative externalities may lead to the overprovision of public investment, but the key message of our analysis is that this result could be reversed when we allow for strategic effect of investment in a two-stage game.

We then proceed with the welfare analysis of fiscal equalization schemes (defined as tax sharing arrangements), which have two opposite effects on equilibrium taxes. The positive effect is to internalize the fiscal externalities that lead to sub-optimally low tax rates. The negative effect is the lowering of the marginal retention rate which reduces the returns to taxation. Indeed, by raising its own tax level, a region drives away some capital causing a reduction in regional output when the extra fiscal revenue is shared with the other region. While the two effects cancel out, and equilibrium taxes are independent of a degree of fiscal equalization, in strike contrast to the perverse fiscal incentives argument, the equalization discourages public investments and produces a welfare gain. Even though public investment increases the rent from capital, the perfect mobility of capital does not allow the local governments to fully appropriate the rent. Since they have to bear the full cost of the investments, the regions are trapped in the prisoner's dilemma situation where they invest because the other does. Fiscal equalization helps to resolve the dilemma by reducing the equilibrium level of investment spending. Since one of the goals of fiscal equalization is to correct fiscal imbalances among regions, we introduce the notion of exogenous regional 
heterogeneity and show that, when the degree of heterogeneity is not too high, each region can benefit from the introduction a "modest" fiscal equalization scheme.

The paper is organized as follows. The next section presents the basic model and derives the benchmark optimal outcome. Section 3 proceeds with the equilibrium analysis in absence of fiscal equalization. The latter is introduced in Section 4. Section 5 concludes. The proofs of most of the results are relegated to the Appendix.

\section{The Model}

Consider a "federation" that consists of two regions $i=1,2$. In both regions the local governments choose a rate of the unit tax $t_{i}$ levied on the mobile tax base (capital) and a level of public investment $g_{i}$ to enhance the productivity of domestic capital. The regions' choices, denoted by $t=\left(t_{1}, t_{2}\right)$ and $g=\left(g_{1}, g_{2}\right)$, determine the allocation of capital $x_{1}$ and $x_{2}$ across regions, the precise mechanism of which will be described below. The production in each region is given by function $F_{i}\left(x_{i} ; g_{i}\right)$, which is increasing, twice continuously differentiable and concave in the level of capital $x_{i}$ for $i=1,2$. Naturally, the capital and investment are

substitutes, so that the cross derivative $\frac{\partial^{2} F_{i}}{\partial x_{i} \partial g_{i}}$ is positive. The cost of the public investment is given by the convex function $c_{i}\left(g_{i}\right)$, which, for analytic tractability, is assumed to be quadratic: $c_{i}\left(g_{i}\right)=g_{i}^{2} / 2$. In this federation a fiscal equalization scheme is implemented whereby both regions share a proportion $\alpha$ of their tax revenue. Even though most of our results can be extended for a larger range of values of $\alpha$, from the practical and technical point of view it would make sense to assume that $0 \leq \alpha \leq 1 / 2$.

Under perfect mobility the allocation of capital across the regions must equate, subject to a reservation price (set equal to zero) for capital, its net return in two regions. We then obtain the following equality:

$$
f_{1}\left(x_{1} ; g_{1}\right)-t_{1}=f_{2}\left(x_{2} ; g_{2}\right)-t_{2}
$$

where $f_{i}$ is the marginal product of the capital in region $i$. We will require that the net return of capital in either region must be nonnegative, since otherwise the regions would be unable to attract any capital. Thus, the value of expression in (1) is greater or equal to zero.

We assume that the regions correctly anticipate how their tax and public investment decision will affect the allocation of capital. By normalizing the total stock of capital to 1, the arbitrage condition (1) determines the amount of the capital in each region, $x_{1}=x_{1}(t, g)$ and $x_{2}(t, g)$. Each region maximizes the welfare function $W_{i}$, the sum of the return to the immobile factor and tax revenue, net of the investment costs:

$$
W_{i}^{\alpha}(t, g)=F_{i}\left(x_{i} ; g_{i}\right)-f_{i}\left(x_{i} ; g_{i}\right) x_{i}+(1-\alpha) t_{i} x_{i}+\alpha t_{j} x_{j}-c_{i}\left(g_{i}\right),
$$

where $i \neq j$. That is, we assume that capital owners are absentee.

An important feature of our model is the gap between regions in terms of their ability to attract the capital. More specifically, we assume that region 1 has a superior production technology, and if the regions choose the same tax and the same public investment level, 
region 1 attracts a larger amount of capital than its counterpart. However this production asymmetry is not irreversible, and it can be mitigated and possibly eliminated by regional public investment choices. Specifically, the production functions are given by

$$
F_{1}\left(x_{1} ; g_{1}\right)=\left(\gamma+g_{1}+\frac{\delta \epsilon}{2}\right) x_{1}-\delta \frac{x_{1}^{2}}{2}, \quad F_{2}\left(x_{2} ; g_{2}\right)=\left(\gamma+g_{2}-\frac{\delta \epsilon}{2}\right) x_{2}-\delta \frac{x_{2}^{2}}{2},
$$

where the parameter $\epsilon \geq 0$ represents the degree of production asymmetry across regions, and $\delta$ is the rate of decline of the marginal product of capital with the amount of capital invested in the region. The regional payoffs simplify to

$$
W_{i}(t, g)=\delta \frac{x_{i}^{2}}{2}+(1-\alpha) t_{i} x_{i}+\alpha t_{j} x_{j}-\frac{g_{i}^{2}}{2} .
$$

The last expression shows that a level of public investments affects the remuneration of the fixed factor through its effect on capital invested in the region. Indeed, (1) yields the following levels of capital in each region:

$$
x_{1}=\frac{1+\epsilon}{2}+\frac{\left(g_{1}-g_{2}\right)-\left(t_{1}-t_{2}\right)}{2 \delta}, \quad x_{2}=\frac{1-\epsilon}{2}-\frac{\left(g_{1}-g_{2}\right)-\left(t_{1}-t_{2}\right)}{2 \delta} .
$$

In particular, under equal tax and investments levels $\left(t_{1}=t_{2}\right.$ and $\left.g_{1}=g_{2}\right)$, region 1 attracts more capital than region 2: $x_{1}(t, g)>1 / 2>x_{2}(t, g)$. Note that the elasticity of the regional tax base size with respect to its own tax and public investment is inversely related to the value $\delta$.

Let us first provide a benchmark by deriving the Pareto optimal allocation that maximizes the total welfare of the federation:

Proposition 2.1 Let $\delta>1$. Then there is an interior Pareto optimal allocation which involves a higher level of investment and capital in region $1: g_{1}^{\circ}=x_{1}^{\circ}=\frac{1}{2}+\beta>g_{2}^{\circ}=$ $x_{2}^{\circ}=\frac{1}{2}-\beta$, where $\beta=\frac{\delta \epsilon}{2(\delta-1)}>0$, and productive efficiency (equal taxation level in both regions) $t_{1}^{\circ}=t_{2}^{\circ}=\gamma-\frac{\delta-1}{2}$.

Note that optimal public investment increases with the amount of capital. At the optimum the remuneration of the mobile factor is taxed away and redistributed to immobile factor $t_{i}=f_{i}=t^{\circ}$. There is more capital allocated to the more attractive region 1 , and, since marginal value of investment (revenue gain) is larger in that region, it also exhibits a higher level of public investment. Note that in our setting the return to the immobile factor is independent of investment level for a given amount of capital. Since the benefit of public investment is to raise fiscal revenue by increasing the marginal return of capital, the optimal investment equals its marginal revenue to its marginal cost in each region. 


\section{Equilibrium - No equalization}

In this section we turn to the examination of regions' equilibrium choices, where, as a benchmark, we first analyze the case without equalizing transfers, i.e., when $\alpha=0$. We assume that regions make public investments before tax decisions so that public investments have a strategic effect on tax choices and regions can attract capital by investing more or taxing less. Attracting more capital increases not only the tax base but also the returns to the immobile factor. Since investment has a negative externality, while taxes' externality effect is positive, one might expect under-taxation and over-investment in equilibrium as in Keen and Marchand (1997) who assumed simultaneous tax and investment choices. However we will show that investment may have important strategic effect on tax choices.

We solve this game backwards and, given the policy choices $t, g$, the allocation of capital, which is correctly anticipated by both regions, is given by (4).

Tax subgame. Given the public investments $g=\left(g_{1}, g_{2}\right)$, each region $i$ anticipates the allocation of capital and independently chooses its tax $t_{i}$ so as to maximize $W_{i}(t, g)$. It is easy to verify that the welfare function is concave in taxes, yielding the following single-valued tax response functions,

$$
\tau_{1}\left(t_{2}\right)=\delta\left(\frac{1+\epsilon}{3}+\frac{g_{1}-g_{2}}{3 \delta}\right)+\frac{t_{2}}{3}, \quad \tau_{2}\left(t_{1}\right)=\delta\left(\frac{1-\epsilon}{3}-\frac{g_{1}-g_{2}}{3 \delta}\right)+\frac{t_{1}}{3} .
$$

Since the best response functions are upward sloping, taxes are strategic complements. Note also that the slope is less than one, which ensures the stability of the equilibrium. By solving the system of equations (5), we derive the Nash equilibrium of the tax subgame:

$$
\widetilde{t}_{1}(g)=\frac{\delta(2+\epsilon)+\left(g_{1}-g_{2}\right)}{4}, \quad \widetilde{t}_{2}(g)=\frac{\delta(2-\epsilon)-\left(g_{1}-g_{2}\right)}{4} .
$$

Thus, there is a negative effect of one region's investment on the other region's second-stage tax choice: $\frac{\partial \widetilde{t}_{2}}{\partial g_{1}}=\frac{\partial \widetilde{t}_{1}}{\partial g_{2}}<0$. Combined with the positive tax externality, investment has a negative strategic effect $\frac{\partial W_{i}}{\partial \widetilde{t}_{j}} \frac{\partial \widetilde{t}_{j}}{\partial g_{i}}<0$ for $i \neq j$.

Public investment. The incentive to invest stems both from the direct effect of investment on regional welfare and its strategic effect on the other region's tax rate. ${ }^{3}$ Even though the latter is negative for both regions, that does not imply that both regions will necessarily reduce their level of investment. Indeed both regions make investment decisions $g_{1}$ and $g_{2}$ in the first-stage and a region may invest more since a low level of investment by the other region raises the marginal value of the former region's investment.

The further examination of the equilibrium allows us to state our next result:

\footnotetext{
${ }^{3}$ By an envelope argument, there is no effect through own tax rate.
} 
Proposition 3.1 Let $\underline{\delta}=3 / 8$. Then under regional asymmetry $(\epsilon>0), \delta>\underline{\delta}$ and $\gamma>\delta-\underline{\delta}$, there exists a unique asymmetric equilibrium, where the public investments, tax levels and allocation of capital in both regions $i=1,2$ are given by:

$$
\begin{aligned}
& g_{1}^{*}=\underline{\delta}+\frac{\underline{\delta} \delta \epsilon}{2(\delta-\underline{\delta})}, \quad g_{2}^{*}=\underline{\delta}-\frac{\underline{\delta} \delta \epsilon}{2(\delta-\underline{\delta})}, \\
& t_{1}^{*}=\delta\left(\frac{1}{2}+\frac{\delta \epsilon}{4(\delta-\underline{\delta})}\right), \quad t_{2}^{*}=\delta\left(\frac{1}{2}-\frac{\delta \epsilon}{4(\delta-\underline{\delta})}\right), \\
& x_{1}^{*}=\frac{1}{2}+\frac{\delta \epsilon}{4(\delta-\underline{\delta})}, \quad x_{2}^{*}=\frac{1}{2}-\frac{\delta \epsilon}{4(\delta-\underline{\delta})} .
\end{aligned}
$$

Region 1 taxes more, invests more and attracts more capital than region 2. Compared to the optimal allocation, there is too little capital and a suboptimal public investment in the more attractive region, and under-taxation in the less attractive region.

The reason for lower level of capital and investment in region 1 is that region 2 will undercut its more attractive rival by under-taxing. This in turn shrinks the amount of capital located in region 1, lowers the marginal value of its investment and reduces it to a suboptimal level.

It is interesting to compare the equilibrium outcome and the optimal allocation in the case of symmetric regions $(\epsilon=0)$. Indeed, $(7)$ implies that $t^{*}=\delta / 2$ and $g^{*}=\underline{\delta}$ are the symmetric baseline equilibrium in taxes and public investments. Comparing with the optimal $\operatorname{tax} t^{\circ}=\gamma-(\delta-1) / 2$ in Proposition 2.1, it is immediate to verify that there is under-taxation for $\gamma>\delta-\underline{\delta}$. Moreover, since $g_{1}^{*}<g^{\circ}=1 / 2$, there is always under-investment. Thus we have the following result:

Proposition 3.2 Under regional symmetry, $\delta>\underline{\delta}$, and $\gamma>\delta-\underline{\delta}$, there is a unique symmetric equilibrium involving under-investment and under-taxation in both regions.

As we argued in the introduction, the under-taxation in equilibrium is a standard consequence of fiscal competition for a mobile tax base, whereas the reason for the underinvestment is a negative strategic effect that exacerbates the tax competition in the second stage.

\section{Equilibrium with Equalization}

Let us turn to the case with equalization $(\alpha>0)$. As in the case without fiscal equalization, we must impose restrictions on the parameters such that the interior equilibrium is stable and the reservation price of capital is respected. The results in this section are valid for $\delta>\underline{\delta}^{\alpha}$ and $\gamma>\underline{\gamma}^{\alpha}$, as defined in the Appendix. Equilibrium tax and investment levels are also given in the Appendix.

We start with symmetric regions where the redistributive effect of fiscal equalization is ruled out. In this case, there are uniform taxes and investment levels, with efficient capital allocation. Equilibrium taxes are independent of the equalization grants (externality 
internalization effect is just offset by the reduction in the retention rate) but, due to the common pool effect, the equilibrium investment levels decrease with the fiscal equalization, and both regions benefit from fiscal equalization. As we indicated in the previous section, in the absence of the equalization scheme, there is under-taxation and under-investment in equilibrium. However, since taxes are independent of fiscal equalization, the entire marginal benefit of investment is assigned to the mobile factor whereas the immobile factor bears the investment cost. This is in contrast to the first best scenario where taxation reduces the mobile factor's return to its reservation value of zero, so that the government recovers the benefit of public investments through taxation.

Proposition 4.1 Suppose $\delta>\underline{\delta}^{\alpha}$ and $\gamma>\underline{\gamma}^{\alpha}$. When regions are symmetric, there is undertaxation and under-investment. Fiscal equāization, which does not affect equilibrium taxes, reduces equilibrium investment levels and generates a welfare improvement for both regions.

This finding supports the second-best analysis view that a reduction in the number of distortions is not necessarily beneficial. In our model equalization affects the investment but not the tax distortion. So we have a somewhat paradoxical result that with undertaxation and under-investment, a joint tax-preserving reduction of investment may be welfare improving. Indeed, when the capital is mobile, the regions cannot tax the full marginal value of investment while incurring its full cost. In equilibrium the regions' investment is a purely defensive device (i.e., each region invests because the other does). Thus, equalization is useful in producing a welfare gain.

In the case of asymmetric regions, the welfare-improving reduction on average investment levels remains. On the other hand, fiscal equalization induces reallocation of capital from the poor to the rich region, which increases the total remuneration of the fixed factor. It is a trivial exercise to show that the total return to the fixed factor is maximized under a corner solution in which one region gets all the capital. Hence, having a more asymmetric capital allocation is good from the total welfare viewpoint. Fiscal equalization also changes total fiscal revenue and the spreading of public investment levels, which can be positive or negative, depending on parameter values. However, it is possible to show that the two positive effects dominate and, as in the asymmetric case, fiscal equalization produces a federation-wide welfare gain.

Proposition 4.2 Suppose $\delta>\underline{\delta}^{\alpha}$ and $\gamma>\underline{\gamma}^{\alpha}$. When regions are asymmetric, fiscal equalization raises the total welfare of the federation.

Finally, we address an interesting question which is whether the more attractive (rich) region could gain from fiscal equalization and the resulting redistribution. We show that the introduction of a "modest" level of fiscal equalization has a positive welfare effect on both regions:

Proposition 4.3 Suppose $\delta>\underline{\delta}^{\alpha}$ and $\gamma>\underline{\gamma}^{\alpha}$. The more attractive region gains from the introduction of a marginal fiscal equalization scheme if either the degree of regional asymmetry $\epsilon$ or the value of $\delta$ is sufficiently small. 
The intuition for this result is easy to grasp. First of all, when regional asymmetry is low, taxes and capital allocation remain almost unchanged under fiscal equalization, and the reduction in public investment raises welfare. Under regional asymmetry, fiscal equalization is beneficial because it raises the share of capital in the more attractive region. However, this comes at the expense of a higher transfer of resources to the poor region, which dominates if regional asymmetry becomes sufficiently high. Finally, the shape of the production function is such that the impact of the asymmetry $\epsilon$ is amplified by $\delta$.

\section{Conclusion}

This paper tackles the issue of equalization grants among heterogenous regions competing in taxes and (market-fostering) public investments when capital is perfectly mobile. In our framework, equalization grants have three effects. Two are efficiency-related (the internalization of the fiscal externality and the incentives for public investments) and the third one is redistributive. We show that equalization is desirable in a variety of settings, both for the federation as a whole as for each region individually, even possibly for the region which is a net contributor to the system provided that the asymmetry among regions is not too high.

The key feature of our analysis is the interplay between two policy choices: marketfostering public investments and capital taxation. The existing literature tends to treat them separately.However these two policy instruments are widely used and very different in nature. Public investments attract capital while taxes drive it away. Moreover equalization grants can have very different effects on taxes and investments (cfr the controversy between the first and second generation of fiscal federalism models). The joint analysis of these two policy instruments reveals that tax competition distorts the public investment choices. Our main result is that, even in the absence of equalization, there is strategic under-investment among regions. This is because public investments raise the stake of tax competition and leads regions to compete more fiercely in taxes. As regards equalization, we find situations where it does not affect equilibrium taxes but only investment choices. The reason is that the marginal retention rate of fiscal revenue also decreases with equalization which discourages efforts to raise taxes. Therefore the classical argument that equalization grants help to correct for the tax externality leading to higher taxes is not always correct.

Our analysis could be related to the economic impact of the last (and possibly future) enlargement(s) of the European Union. As the European Economic and Social Committee states $^{4}$

Western members have expressed fear that the new members may represent too much of a burden for their own economies or the European budget. (...) The public debate now focuses on wage and tax competition, which would be used by new members to attract production facilities and jobs.

Our results suggest that "old" member states may benefit from setting up equalization grants all around if they are concerned by the competition from the "new" member states to attract capital.

\footnotetext{
${ }^{4}$ Available online at http://www.esc.eu.int/documents/program_ifri_en.pdf
} 


\section{Appendix}

Proof of Proposition 2.1: To determine a Pareto optimal allocation we have to find

$$
\begin{aligned}
\max _{x_{i}, t_{i}, g_{i}} \Lambda & =\sum_{i} W_{i}(t, g)+v\left[\sum_{i} x_{i}-1\right]+\sum_{i} \mu_{i}\left[t_{i}-f_{i}\left(x_{i} ; g_{i}\right)\right] \\
& =\delta \frac{x_{1}^{2}}{2}+t_{1} x_{1}-\frac{g_{1}^{2}}{2}+\delta \frac{x_{2}^{2}}{2}+t_{2} x_{2}-\frac{g_{2}^{2}}{2}+v\left[\sum_{i} x_{i}-1\right] \\
& +\mu_{1}\left[t_{1}-\left(\gamma+g_{1}+\frac{\delta \epsilon}{2}-\delta x_{1}\right)\right]+\mu_{2}\left[t_{2}-\left(\gamma+g_{2}-\frac{\delta \epsilon}{2}-\delta x_{2}\right)\right] .
\end{aligned}
$$

By the first order condition (FOC) on $t_{i}, \mu_{i}=-x_{i}$ which, using the FOCs on $x_{i}$ and $g_{i}$ implies, respectively, that $t_{i}=v$, i.e, $t_{1}=t_{2}$ and, $g_{i}=x_{i}$. Combining the FOCs on $t_{i}$ and $v$ together with the above identities, we have

$$
\gamma+g_{1}+\frac{\delta \epsilon}{2}-\delta g_{1}=\gamma+\left(1-g_{1}\right)-\frac{\delta \epsilon}{2}-\delta\left(1-g_{1}\right)
$$

and by solving for $g_{1}$ and the remaining variables, we obtain

$$
t_{1}^{\circ}=t_{2}^{\circ}=\gamma-\frac{\delta-1}{2}, g_{1}^{\circ}=x_{1}^{\circ}=\frac{1}{2}+\frac{\delta \epsilon}{2(\delta-1)}, g_{2}^{\circ}=x_{2}^{\circ}=\frac{1}{2}-\frac{\delta \epsilon}{2(\delta-1)} .
$$

It can be shown that the second order condition (SOC) is satisfied for $\delta>1$.

Proof of Proposition 3.1: Plugging expressions (4) for equilibrium taxes into (6) we obtain $\widetilde{x}_{1}(g)=\frac{1+\epsilon / 2}{2}+\frac{g_{1}-g_{2}}{4 \delta}$. Since region 1 correctly anticipates the equilibrium of the tax subgame and the capital allocation, to maximize its welfare, it chooses the level of its public investment taking as given the investment choice of region 2. FOC is

$$
\frac{d W_{1}}{d g_{1}}=\frac{\partial W_{1}}{\partial g_{1}}+\frac{\partial W_{1}}{\partial \widetilde{x}_{1}} \frac{\partial \widetilde{x}_{1}}{\partial g_{1}}+\frac{\partial W_{1}}{\partial \widetilde{t}_{1}} \frac{\partial \widetilde{t}_{1}}{\partial g_{1}}=\frac{\widetilde{x}_{1}}{2}+\frac{\widetilde{t}_{1}}{4 \delta}-g_{1}
$$

The substitution for $\widetilde{t}_{1}$ and $\widetilde{x}_{1}$ yields

$$
\frac{d W_{1}}{d g_{1}}=\frac{3}{4}\left(\frac{1+\epsilon / 2}{2}+\frac{g_{1}-g_{2}}{4 \delta}\right)-g_{1}=0 .
$$

Note that SOC is given by $\frac{d^{2} W_{1}}{d^{2} g_{1}}=-1+\frac{3}{16 \delta}<0$ and it holds when $\delta>3 / 16$. By using similar derivations for region 2, we obtain the expressions for best replies

$$
\mathcal{G}_{1}\left(g_{2}\right)=\frac{\delta(2+\epsilon)-g_{2}}{(16 / 3) \delta-1}, \quad \mathcal{G}_{2}\left(g_{1}\right)=\frac{\delta(2-\epsilon)-g_{1}}{(16 / 3) \delta-1} .
$$


Notice that, for $\delta>3 / 16$, the best-response functions are downward sloping, and so public investments are strategic substitutes. Moreover, the stability of the public investment equilibrium requires that $\delta>\underline{\delta} \equiv 3 / 8$. Assume hereafter that $\delta>\underline{\delta}$ and $\gamma>\delta-\underline{\delta}$. The solution of the system of equations (8) yields the equilibrium investment levels

$$
g_{1}^{*}=\underline{\delta}+\frac{\underline{\delta} \delta \epsilon}{2(\delta-\underline{\delta})}, \quad g_{2}^{*}=\underline{\delta}-\frac{\underline{\delta} \delta \epsilon}{2(\delta-\underline{\delta})},
$$

and, subsequently, the tax equilibrium

$$
t_{1}^{*}=\delta\left(\frac{1}{2}-\frac{\delta \epsilon}{4(\delta-\underline{\delta})}\right), \quad t_{2}^{*}=\delta\left(\frac{1}{2}-\frac{\delta \epsilon}{4(\delta-\underline{\delta})}\right) .
$$

Therefore $t_{1}^{*}-t_{2}^{*}>0$ and $g_{1}^{*}-g_{2}^{*}>0$. The equilibrium allocation of capital is $x_{1}^{*}=$ $\frac{1}{2}+\frac{\delta \epsilon}{4(\delta-\underline{\delta})}>x_{2}^{*}$. Finally, notice that the reservation price of capital is respected in both jurisdictions for $\gamma>\delta-\underline{\delta}>0$ since $f_{1}\left(x_{1}^{*} ; g_{1}^{*}\right)-t_{1}^{*}=f_{2}\left(x_{2}^{*} ; g_{2}^{*}\right)-t_{2}^{*}=\frac{3}{8}+\gamma-\delta$.

In order to provide the proofs of the results in Section 4, we should first derive a $s$ subgame perfect Nash equilibrium under equalization. First note that fiscal equalization does not change the allocation of capital as a function of policy choices in (4). Solving backwards, we first compute the equilibrium of the tax subgame as a function of investment choices $g$. Differentiating $W_{i}^{\alpha}(t, g)$ in (2) with respect to $t_{i}$ yields FOC

$$
\frac{\partial W_{i}^{\alpha}}{\partial t_{i}}=\left(\frac{1}{2}-\alpha\right) x_{i}-(1-\alpha) \frac{t_{i}}{2 \delta}+\alpha \frac{t_{j}}{2 \delta}=0 .
$$

By using (4) to substitute for $x_{i}$, we notice that SOC is satisfied: $\frac{\partial^{2} W_{i}^{\alpha}}{\partial t_{i}^{2}}=\frac{4 \alpha-3}{4 \delta}<0$ for all $\alpha \in[0,1 / 2]$. Thus, we obtain the following tax response functions

$\tau_{1}\left(t_{2} ; \alpha\right)=K_{1} K_{2}\left[\delta(1+\epsilon)+\left(g_{1}-g_{2}\right)\right]+K_{2} t_{2}, \quad \tau_{2}\left(t_{1} ; \alpha\right)=K_{1} K_{2}\left[\delta(1-\epsilon)-\left(g_{1}-g_{2}\right)\right]+K_{2} t_{1}$, where $K_{1}=1-2 \alpha$ and $K_{2}=(3-4 \alpha)^{-1}$. It allows us to derive the equilibrium tax levels as functions of $g_{1}$ and $g_{2}$ :

$$
\widetilde{t}_{1}(g ; \alpha)=\frac{\delta}{2}+\frac{K_{1} K_{3}}{4}\left(\delta \epsilon+\left(g_{1}-g_{2}\right)\right), \quad \widetilde{t}_{2}(g ; \alpha)=\frac{\delta}{2}-\frac{K_{1} K_{3}}{4}\left(\delta \epsilon+\left(g_{1}-g_{2}\right)\right),
$$

where $K_{3}=(1-\alpha)^{-1}$. Substituting (11) into (4) yields

$$
\widetilde{x}_{1}(g ; \alpha)=\frac{1}{2}+K_{3}\left(\frac{\epsilon}{4}+\frac{g_{1}-g_{2}}{4 \delta}\right), \quad \widetilde{x}_{2}(g ; \alpha)=\frac{1}{2}-K_{3}\left(\frac{\epsilon}{4}+\frac{g_{1}-g_{2}}{4 \delta}\right) .
$$

Anticipating tax choices and capital allocation, each region $i$ chooses its public investment $g_{i}$ given the choice of the other region $g_{j}$, and FOC is

$$
\frac{d W_{i}^{\alpha}}{d g_{i}}=\frac{\partial W_{i}^{\alpha}}{\partial g_{i}}+\frac{\partial W_{i}^{\alpha}}{\partial \widetilde{x}_{i}} \frac{\partial \widetilde{x}_{i}}{\partial g_{i}}+\frac{\partial W_{i}^{\alpha}}{\partial \widetilde{t}_{j}} \frac{\partial \widetilde{t}_{j}}{\partial g_{i}}=-g_{1}+\frac{\widetilde{x}_{1}}{2}+\frac{\widetilde{t}_{1}}{4 \delta}-\alpha K_{3} \frac{\widetilde{t}_{2}}{4 \delta}-\frac{\alpha}{4} K_{1} K_{3}=0 .
$$


(Note that $\operatorname{SOC} \frac{d^{2} W_{i}^{\alpha}}{d g_{i}^{2}}=\frac{K_{3}^{2}}{16 \delta K_{2}}-1<0$ holds for $\delta>\underline{\delta}^{\alpha}=\frac{K_{3}^{2}}{8 K_{2}}$.

The best replies are

$$
\mathcal{G}_{1}^{\alpha}\left(g_{2}\right)=K_{4}+\left(\delta \epsilon-g_{2}\right) K_{5}, \quad \mathcal{G}_{2}^{\alpha}\left(g_{1}\right)=K_{4}-\left(\delta \epsilon+g_{1}\right) K_{5},
$$

where $K_{4}=\delta \frac{2 K_{3}^{-1}\left(3 K_{1}+4 \alpha^{2}\right)}{16 \delta K_{3}^{-2}-K_{2}^{-1}}$ and $K_{5}=\frac{K_{2}^{-1}}{16 \delta K_{3}^{-2}-K_{2}^{-1}}$.

Thus, public investments are strategic substitutes and the Nash equilibrium is stable if $\delta>\underline{\delta}^{\alpha}$ and $\underline{\delta}^{\alpha} \in[\underline{\delta}, 1 / 2]$. It follows that equilibrium taxes and investment levels are given by

$$
\begin{array}{r}
t_{1}^{*}(\alpha)=t^{*}+\frac{\delta^{2}}{4} K_{3} K_{1} \frac{\epsilon}{\delta-\underline{\delta}^{\alpha}}, \quad t_{2}^{*}(\alpha)=t^{*}-\frac{\delta^{2}}{4} K_{3} K_{1} \frac{\epsilon}{\delta-\underline{\delta}^{\alpha}}, \\
g_{1}^{*}=g^{*}(\alpha)+\frac{K_{3}^{2}}{16 K_{2}}\left(\frac{\delta \epsilon}{\delta-\underline{\delta}^{\alpha}}\right), \quad g_{2}^{*}=g^{*}(\alpha)-\frac{K_{3}^{2}}{16 K_{2}}\left(\frac{\delta \epsilon}{\delta-\underline{\delta}^{\alpha}}\right),
\end{array}
$$

where the baseline symmetric tax and investment levels are $t^{*}=\frac{\delta}{2}$ and $g^{*}(\alpha)=\frac{1}{8}\left(2 K_{1}+K_{3}\right)$. This yields the equilibrium capital allocation

$$
x_{1}^{*}(\alpha)=\frac{1}{2}+\frac{\delta \epsilon K_{3}}{4\left(\delta-\underline{\delta}^{\alpha}\right)}, \quad x_{2}^{*}(\alpha)=\frac{1}{2}-\frac{\delta \epsilon K_{3}}{4\left(\delta-\underline{\delta}^{\alpha}\right)} .
$$

Hence, for $\delta>\underline{\delta}^{\alpha}$, there is a stable Nash equilibrium in which the more attractive region invests more in public infrastructures, sets a higher tax rate, and attracts more capital than the less attractive one. Finally, it is straightforward to verify that the reservation price of capital is respected in both jurisdictions for $\gamma>\underline{\gamma}^{\alpha}=\delta-\left(K_{2}^{-1}+\alpha K 3\right) / 8$.

Proof of Proposition 4.1: It is easy to show that

$$
\frac{\partial W_{1}^{*}}{\partial \alpha}=\delta x_{1}^{*} \frac{d x_{1}^{*}}{d \alpha}+t_{1} \frac{d x_{1}^{*}}{d \alpha}+x_{1} \frac{d t_{1}^{*}}{d \alpha}-g_{1}^{*} \frac{d g_{1}^{*}}{d \alpha}=-g_{1}^{*} \frac{-4+K_{3}^{2}}{8}>0,
$$

where $K_{3}^{2}=(1-\alpha)^{-2}<4$ for $0<\alpha<1 / 2$.

Proof of Proposition 4.2: Straightforward, but tedious, computations yield

$$
\frac{d\left(W_{1}^{* \alpha}+W_{2}^{* \alpha}\right)}{d \alpha}=\frac{K_{1} K_{3}^{3}}{32}\left(\left(K_{2}^{-1}+2 \alpha\right)\left(K_{3}^{-1} K_{2}^{-1}+\alpha\right)+\frac{4 \delta^{4} \epsilon^{2}}{\left(\delta-\underline{\delta}^{\alpha}\right)^{3}}\right)>0 .
$$

Proof of Proposition 4.3: When $\alpha=0$, the capital in region 1 is given by $x_{1}^{*}=$ $\frac{1}{2}+\frac{2 \delta \epsilon}{8 \delta-3}$, which is smaller than 1 if $\epsilon<\bar{\epsilon}_{0}=(8 \delta-3) / 4 \delta$. Denote by $Z(\epsilon)$ the partial derivative (with respect to $\alpha$ ) of the welfare of the more attractive region $\frac{\partial W_{1}^{*}}{\partial \alpha}$, evaluated at $\alpha=0$. We shall show that the value of $Z$ is positive under the conditions of the proposition. 
We have

$$
Z(\epsilon)=\frac{32 \delta^{4}}{(8 \delta-3)^{3}} \epsilon^{2}-\frac{3 \delta(8 \delta-1)(16 \delta-9)}{16(8 \delta-3)^{2}} \epsilon+\frac{9}{64}
$$

Let the two roots of the equation $Z(\epsilon)=0$ be denoted by $\epsilon_{1}$ and $\epsilon_{2}$. It can be verified that both exist if $\delta>\tilde{\delta} \approx 1.0202$. Since $Z(0)>0$, the straightforward examination yields the following cases: when $\delta<\tilde{\delta}, Z(\epsilon)>0$ for all $\epsilon>0$; when $\tilde{\delta}<\delta<9 / 8, Z(\epsilon)>0$ for $\epsilon<\epsilon_{1}$ and $\epsilon>\epsilon_{2}$; and if $\delta>9 / 8, Z(\epsilon)>0$ for $\epsilon<\epsilon_{1}$. This implies, that $Z(\epsilon)>0$ if either $\epsilon<\epsilon_{1}$ or $\delta<\tilde{\delta}$. $\square$

\section{References}

[1] Ahmad, E. and R. Thomas, 1997, Types of Transfers: a General Formulation, in Financing Decentralized Expenditures: An International Comparison of Grants, E. Ahmad, ed., Aldershot UK: Eward Elgar.

[2] Baretti, C., B. Huber and K. Lichtblau, 2002, A Tax on Tax Revenue: the Incentive Effects of Equalizing Transfers: Evidence from Germany, International Tax Journal 9, $631-49$.

[3] Bird, R. and E. Slack, 1990, Equalization: The Representative Tax System Revisited, Canadian Tax Journal 38, 913-27.

[4] Boadway, R. and F. Flatters, 1982, Efficiency and Equalization Payments in a Federal System of Government: A Synthesis and Extension of Recent Results, Canadian Journal of Economics 15, 613-33.

[5] Bordignon, M., P. Manasse and G. Tabellini, 2001, Optimal Regional Redistribution under Asymmetric Information, American Economic Review, 91(3), 709-23.

[6] Bucovetsky, S. and M. Smart, 2006. The Efficiency Consequences of Local Revenue Equalization: Tax Competition and Tax Distortions, Journal of Public Economic Theory 8(1), 119-44.

[7] Buettner, T., 2006, The Incentive Effect of Fiscal Equalization Transfers on Tax Policy, Journal of Public Economics 90(3), 477-97.

[8] Careaga, M., and B. R. Weingast, 2000, The Fiscal Pact with the Devil: A Positive Approach to Fiscal Federalism, Revenue Sharing, And Good Governance, Working Paper, Hoover Institution, Stanford University.

[9] Dahlby, B. and N. Warren, 2003, Fiscal Incentive Effects of the Australian Equalization System, Economic Records 79, 434-45.

[10] Figuières, C., J. Hindriks and G. Myles, 2004, Revenue Sharing versus Expenditure Sharing, International Tax and Public Finance 11, 155-74. 
[11] Fudenberg, D. and J. Tirole, 1984, The FatCat Effect, the Puppy-Dog Ploy, and the Lean and Hungry Look, American Economic Review, Papers and Proceedings 74(2), 361-66.

[12] Hepp, R. and J. von Hagen, 2001, Regional Risksharing and Redistribution in the German Federation, CEPR Discussion Papers 2662.

[13] Hindriks, J., and G.D. Myles, 2003, Strategic Inter-regional Transfers, Journal of Public Economic Theory 5(2), 229-48.

[14] Jin, H., Y. Qian and B.R. Weingast, 2005, Regional Decentralization and Fiscal Incentives: Federalism, Chinese Style, Journal of Public Economics 89 (9-10), 1719-42.

[15] Keen, M., and M. Marchand, 1997, Fiscal Competition and the Pattern of Public Spending, Journal of Public Economics 66(1), 33-53.

[16] Kothenburger, M, 2002, Tax Competition and Fiscal Equalization, International Tax Journal 9 (4), 391-408.

[17] Parikh, S. and B.R. Weingast (2003), Partisan Politics and the Structure and Stability of Federalism, Indian Style, Working Paper, Stanford Center for International Development, Stanford University.

[18] Shah, A., 2004, Fiscal Decentralization in Developing and Transition Economies: Progress, Problems, and the Promise, Policy Research Working Paper Series 3282, The World Bank.

[19] Shleifer, A. and R.W. Vishny, 1998, Government in Transition, Chapter 11 in Shleifer and Vishny, 1998, The Grabbing Hand: Government pathologies and their cures, Harvard University Press, Cambridge, MA.

[20] Smart, M., 1998, Taxation and Deadweight Loss in a System of Intergovernmental Transfers, Canadian Journal of Economics, 31(1), 189-206.

[21] Weingast, B.R., 2006, Second Generation Fiscal Federalism: Implication for Decentralized Democratic Governance and Economic Development, Working Paper, Hoover Institution, Stanford University.

[22] Wildasin, D., 1991, Income Redistribution in a Common Labor Market, American Economic Review, 81(4), 757-74.

[23] Zhuravskaya, E., 2000, Incentives to Provide Local Public Goods: Fiscal Federalism Russian Style, Journal of Public Economics 76(3), 337-68. 
Département des Sciences Économiques de l'Université catholique de Louvain

Institut de Recherches Économiques et Sociales

Place Montesquieu, 3

1348 Louvain-la-Neuve, Belgique 